\title{
REVIEW
}

\section{Metallic nanostructures for light trapping in energy-harvesting devices}

\author{
Chuan Fei Guo', Tianyi Sun ${ }^{1}$, Feng Cao ${ }^{1}$, Qian Liu ${ }^{2}$ and Zhifeng Ren ${ }^{1}$
}

Solar energy is abundant and environmentally friendly. Light trapping in solar-energy-harvesting devices or structures is of critical importance. This article reviews light trapping with metallic nanostructures for thin film solar cells and selective solar absorbers. The metallic nanostructures can either be used in reducing material thickness and device cost or in improving light absorbance and thereby improving conversion efficiency. The metallic nanostructures can contribute to light trapping by scattering and increasing the path length of light, by generating strong electromagnetic field in the active layer, or by multiple reflections/absorptions. We have also discussed the adverse effect of metallic nanostructures and how to solve these problems and take full advantage of the light-trapping effect.

Light: Science \& Applications (2014) 3, e161; doi:10.1038/lsa.2014.42; published online 25 April 2014

Keywords: conversion efficiency; light trapping; photovoltaics; plasmonics; solar absorber

\section{INTRODUCTION}

The conversion of solar energy to electricity or heat might be the ultimate means to help solve the energy crisis when hydrocarbon resources such as coal and other fossil fuels cannot satisfy the energy demand. Solar energy is abundant, $\sim 5000$ times our current power consumption. ${ }^{1}$ The use of solar energy can also reduce the environmental problems caused by the consumption of fossil fuels by reducing dusts, noxious gases and greenhouse gases, as well as the resulting haze, acid rain and global warming. To date, the worldwide installed capacity of solar harvesting devices is $\sim 60 \mathrm{GW}$ in electric energy and $\sim 300 \mathrm{GW}$ in thermal energy, ${ }^{2}$ with an annual rapid increase. For the existing technology, there is room for further improvement by either enhancing the light absorption or avoiding loss of electricity or heat after absorption. Recently, new advances in nanotechnology and material fabrication methods have resulted in an emerging field of plasmonics by properly introducing metallic nanostructures to manipulate light, enabling light trapping in active layers and thereby enhancing the performance of energy-harvesting devices. ${ }^{3}$ In addition, certain highly absorbing surfaces or structures with broadband absorption promising to extend the working wavelength of the solar energy spectrum (Figure 1) have been realized. The light-trapping effect, however, allows the thickness of materials and the costs of solar cells to decrease, which in turn benefits electricity collection when the minor carrier diffusion length in the active layer is not sufficiently long.

In this review, we focus on light trapping induced by metallic nanostructures for solar energy collection. Corresponding applications are not only for photovoltaics, but also for solar thermal. In fact, solar thermal has a market with profit even higher than photovoltaics, yet has not received enough attention. Solar thermal devices can absorb light from ultraviolet to near infrared (IR) $(0.3-2 \mu \mathrm{m})$, which is much broader than the wavelength that any single-junction solar cells can absorb (Figure 1). The conversion efficiency of solar thermal devices (such as solar water heaters) is also much higher; for example, an evacuated tube collector can have an efficiency of approximately $80 \%$ in the summer. Such solar water heaters have been widely used in China and Europe and are quite effective in $\mathrm{CO}_{2}$ reduction. ${ }^{2}$

\section{PLASMONICS FOR LIGHT TRAPPING IN PHOTOVOLTAICS}

Photovoltaic devices can covert solar energy into electricity. Commercial crystalline silicon (c-Si) solar cell technologies often adopt a basic etching process to produce pyramids to reflect light back into silicon and hence improve the absorbance. A silicon nitride layer is then applied onto the pyramids to act both as a passivation layer and as an antireflective coating (ARC). The MA Green group at the University of New South Wales has performed important pioneering work on thick Si solar cells. This group achieved an efficiency of $\sim 25 \%$ for single c-Si solar cells ${ }^{4,5}$ and $19.8 \%$ for polycrystalline Si solar cells using the light-trapping structures of inverted pyramids and a honeycomb structure, ${ }^{5}$ respectively. However, c-Si is not a highly absorbing material and requires a thickness of $>100 \mu \mathrm{m}$ to enable nearly complete light absorption. While, too thick of a material is not good for electricity collection because the thickness must be at least several times smaller than the minority carrier diffusion length. Reducing the thickness of the active layer can therefore reduce the recombination of carriers and improve the conversion efficiency. By contrast, thin film solar cells, which use highly absorbing materials such as amorphous

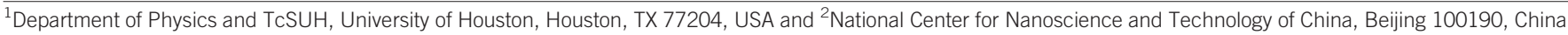
Correspondence: Professor Q Liu, National Center for Nanoscience and Technology of China, No. 11 Beiyitiao Zhongguancun, Beijing 100190, China

E-mail: liuq@nanoctr.cn

Or Professor ZF Ren, Department of Physics and TcSUH, University of Houston, Houston, TX 77204, USA

E-mail: zren@uh.edu

Received 22 September 2013; revised 4 November 2013; accepted 15 November 2013 


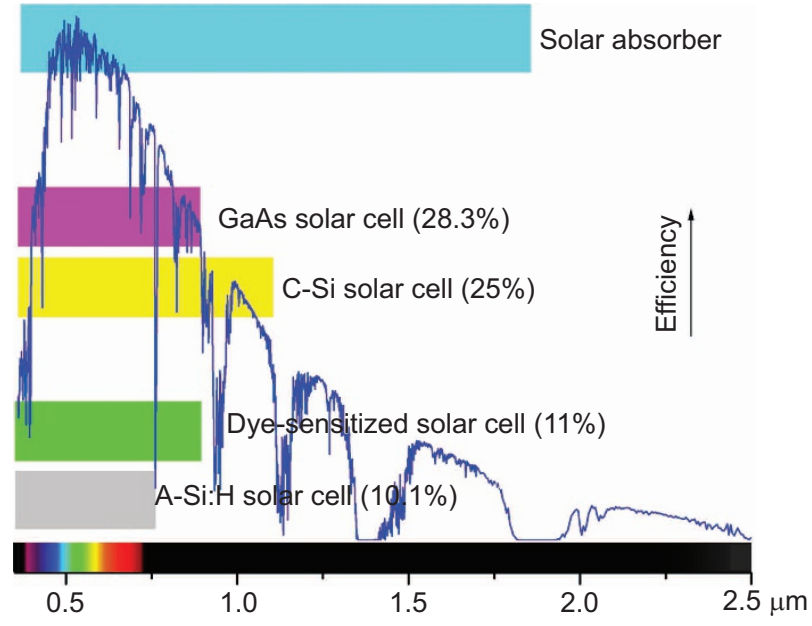

Figure 1 Solar spectrum and the working wavelength and comparison of efficiency for various solar-energy-harvesting mechanisms. A-Si, amorphous silicon; C-Si, crystalline silicon.

silicon (a-Si), GaAs and $\mathrm{CuIn}_{x} \mathrm{Ga}_{1-x} \mathrm{Se}_{2}$, require a film thickness of only hundreds of nanometers to microns. Thin film solar cell technologies can largely reduce the use of semiconducting materials and the cost. In addition, thin films can be easily deposited onto many inexpensive substrates including glass, metals, or polymers. If the active layer can be further reduced to $\sim 10 \mathrm{~nm}$, the semiconductors, especially those are properly patterned, will be extremely flexible ${ }^{6}$ such that they can be used in flexible solar cells, which might act as the power source for electronic skins and foldable photoelectronics. ${ }^{7}$ The main problem for thin film solar cells is that the materials exhibit very small absorbance of nearbandgap light, and reducing the thickness will further cause a significant loss of absorption, therefore leading to a limited efficiency.

The emerging area of plasmonics offers new paths for improving the efficiency of thin solar cells. There are three extensively investigated plasmonic structures integrated in thin cells that can remarkably decrease the thickness of photovoltaic materials while maintaining good absorbance, ${ }^{3,8}$ as shown in Figure 2. First, metallic nanoparticles on top of a solar cell can scatter a broad range of sunlight to couple and trap freely propagating plane waves in the thin film by folding the light into a thin absorber layer (Figure $2 \mathrm{a}$ ). In this case, the angular redistribution of the scattered light and back contact reflection also increase the optical path length and therefore, contribute to light trapping. Second, embedded metallic nanoparticles can be used as subwavelength antennas for which the excited localized surface plasmons couple with the semiconductor, increasing its effective absorption crosssection (Figure 2b). Third, a patterned metallic back contact of a thin photovoltaic absorber layer can couple sunlight into surface plasmonic polariton (SPP) modes that are supported at the semiconductor/ metal interface (Figure 2c). Light in the propagating waveguide mode is absorbed in the plane of the semiconductor, while carrier collection occurs out of plane, allowing for a reduction in overall thickness. ${ }^{8}$

\section{Scattering effect of metallic nanoparticles for light trapping}

There have been many experiments that prove the light trapping of metal nanoparticles utilizing the scattering effect. In 2005, Yu and coworkers ${ }^{9}$ deposited Au nanoparticles on a thick Si p-n junction diode; they observed enhancement of optical absorption and photocurrent via the excitation of surface plasmon resonances in spherical Au nanoparticles. In fact, early in 1998, Stuart and co-workers ${ }^{10}$ utilized metallic nanoparticle for improved photodetectors. And in photovoltaic applications, $\mathrm{Yu}$ et al. ${ }^{11}$ also observed that metal nanoparticles with a modest density could lead to an efficiency enhancement of $8.3 \%$ (corresponding power output increases from 2.77 to $3.00 \mathrm{~mW} \mathrm{~cm}^{-2}$ ) in an amorphous Si thin cell for which the active layer was only $240 \mathrm{~nm}$ thick. Green et al. ${ }^{12}$ investigated the light-trapping effect using Ag nanoparticles on a $1.25-\mu \mathrm{m}$-thick c-Si on an insulator solar cell and reported a broadband enhancement and a 16-fold enhancement at $1050 \mathrm{~nm}$. Atwater et al. ${ }^{13}$ demonstrated that GaAs thin cells exhibit an improvement of $8 \%$ for the short circuit current density with templated high aspect-ratio Ag nanoparticles, and these nanoparticles not only scatter light, but also decrease the top contact sheet resistance. The thin cells with Ag nanoparticles yield a significant enhancement for wavelengths longer than $600 \mathrm{~nm}$ (Figure 3). ${ }^{13}$ When using a periodic array of metal nanoparticles for light trapping, the grating pitch should be selected to allow higher order diffraction modes for long wavelengths while maintaining the highest possible fill factor. For example, a set of optimal parameters for light trapping in Si solar cells is a particle size of $\sim 200 \mathrm{~nm}$ and a pitch of $\sim 400 \mathrm{~nm} .^{14}$

The particle shape, size, distance from the semiconductor and refractive index of the medium could all affect the coupling efficiency. ${ }^{3,11,15-17}$ Nanospheres are the most commonly used scattering centers. Figure $4 \mathrm{a}$ and $4 \mathrm{~b}$ show the normalized scattering cross section of spherical particles as a function of wavelength and particle size in both air and $\mathrm{Si}^{17}$ The plasmonic resonance exhibits an obvious redshift effect in silicon (which has a higher refractive index compared with air). In addition, the resonance peaks redshift and broaden with increasing particle sizes. This redshift significantly enhances the light trapping in the red and near-IR region, which is otherwise a low absorption region for Si. Typically, particles with a size of $\sim 100 \mathrm{~nm}$ can provide the highest scattering efficiency. Particle shape should also be considered. Cylindrical and hemispherical particles exhibit higher path length enhancements than spherical particles. ${ }^{3,15,16}$ This effect is evidenced in Figure 4c, which reveals the difference in fraction of light
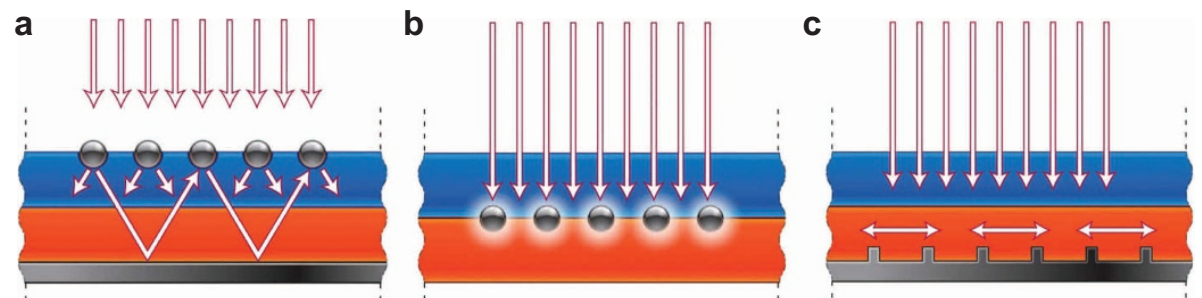

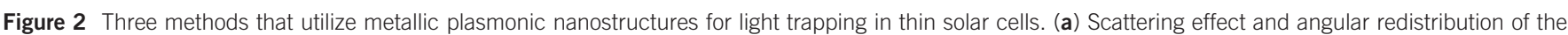

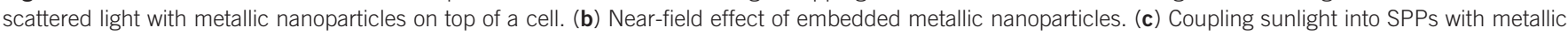
nanostructures on the rear contact. Blue: ARC; orange: active layer; gray: metal. Figure reproduced with permission from Ref. 3 , C 2010 Macmillan Publishers Ltd. ARC, antireflective coating; SPP, surface plasmonic polariton. 

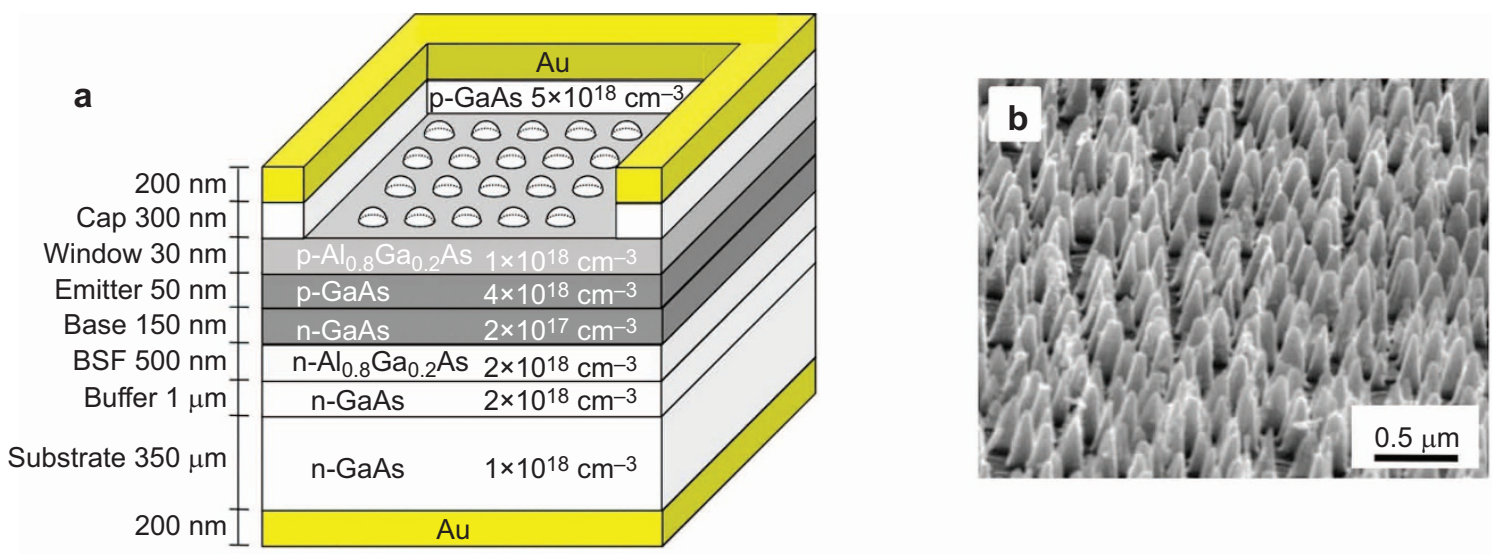

\section{C}

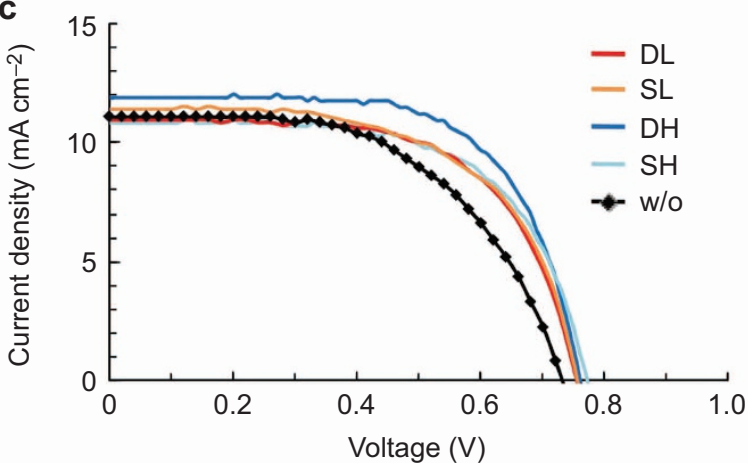

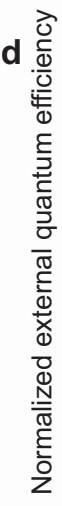

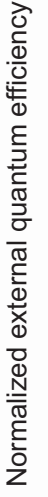

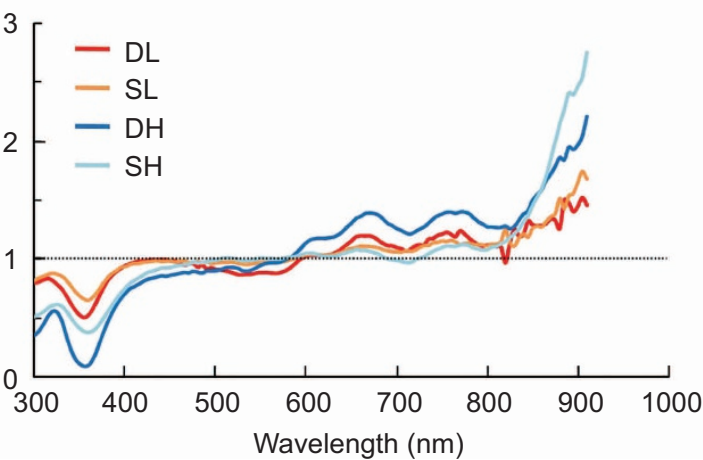

Figure 3 (a) The layered structure of a GaAs solar cell with Au nanoparticles on top. (b) Scanning electron microscopy (SEM) image of densely formed high aspect-ratio Au nanoparticles. (c) Photovoltaic $I-V$ curves for the GaAs solar cells under AM 1.5 illumination. (d) Normalized spectral responses for the GaAs solar cells. A solar cell without Ag nanoparticles (w/o) on top was used as a reference. Figure reproduced with permission from Ref. 13, ( 2008 AIP. AM, air mass; BSF, black surface field; $\mathrm{DH}$, densely formed high nanoparticles $\left(3.3 \times 10^{9} \mathrm{~cm}^{-2}\right.$ density/220 nm height); DL, densely formed low nanoparticles $\left(3.3 \times 10^{9} \mathrm{~cm}{ }^{-2}\right.$ density $/ 55 \mathrm{~nm}$ height); SH, sparsely formed high nanoparticles $\left(1.8 \times 10^{9} \mathrm{~cm}^{-2}\right.$ density $/ 220 \mathrm{~nm}$ height); SL, sparsely formed high particles $\left(1.8 \times 10^{9} \mathrm{~cm}^{-2} \mathrm{density} / 55 \mathrm{~nm}\right.$ height).

scattered into semiconductor substrates with nanocylinder, hemisphere, sphere and large sphere (scattered light decreases with the same order). However, nanospheres can be easily synthesized such that they are still widely used. Figure $4 \mathrm{~d}$ shows that for a point dipole, the fraction of light scattered into a semiconductor substrate decreases with increasing distance to the underlying Si substrate. However, the decrease is not dramatic; for example, the fraction of light is $84 \%$ when the dipole is $60 \mathrm{~nm}$ away from the substrate. ${ }^{16}$ It is often not recommended that the nanoparticles be placed directly on the active layer, as this placement causes a carrier recombination problem. In fact, the effective scattering crosssection can be increased by increasing the distance between the nanoparticles and the substrate, as this distance prevents destructive interference effects between the incident and reflected fields, although it comprises the near-field coupling. ${ }^{3,17}$ The interference problem can also be solved by placing the nanoparticles on the rear of the solar cells. In this case, short wavelength light can be largely absorbed by the semiconducting materials, while long wavelength light, e.g., IR and red light that reaches the rear of the cell can be scattered by the nanoparticles and be trapped. ${ }^{18}$ In addition, $\mathrm{Ag}$ is a better metal than $\mathrm{Au}$ as $\mathrm{Ag}$ particles yield much higher path length enhancements than $\mathrm{Au}$ particles ${ }^{15}$ and offer a lower price. In addition to metal nanoparticles, other structures such as gratings with ARC could also result in absorption enhancement in ultrathin solar cells due to improved coupling to guided modes. ${ }^{19}$

\section{Near-field effect of metallic nanoparticles in solar cells}

Another method for light trapping is to make use of the strong local field of very small metallic nanoparticles. Metallic nanoparticles are often mixed with or embedded in active materials such that the surrounding active materials can become highly absorbed due to the high density of states of the phonons and the fact that the nanoparticles can directly excite charge carriers. Considering the fabrication method, this mechanism is especially suitable for preparing dye-sensitized solar cells using solution processes. ${ }^{20}$ The small particle size and close particle-to-particle spacing often help to further enhance the near-field effect; however, the small nanoparticles do not exhibit a great scattering effect. ${ }^{3}$ This near-field mechanism works well for materials in which the carrier diffusion lengths are small, and photocarriers must thus be generated near the collection junction area. The absorption rate in the semiconductor must be larger than the reciprocal of the typical plasmon decay time to avoid dissipation of the absorbed energy into ohmic damping in the metal. ${ }^{3}$ The optical thickness of organic thin films is typically larger than the carrier diffusion length, thus reducing the thickness while maintaining the absorbance in organic solar cells is significant. Embedded nanoparticles of Ag could efficiently increase the light absorption in ultrathin organic solar cells and thereby improve the efficiency. ${ }^{21}$ By incorporating electrodeposited $13 \mathrm{~nm}$ Ag nanoparticles on surface-modified transparent electrodes, the efficiency of organic solar cells could increase from $3.05 \%$ to $3.69 \%$ because of the improved absorbance via the strongly enhanced local electromagnetic field in the vicinity of the Ag nanoparticles. ${ }^{22} \mathrm{Au}$ nanoparticles could also lead to an efficiency improvement in polymer bulk heterojunction solar cells. ${ }^{23,24}$ However, metal nanoparticles may also degrade the carrier mobility and thus compromise the benefit of the near-field enhancement. ${ }^{25}$ Enhanced efficiency or photocurrent 

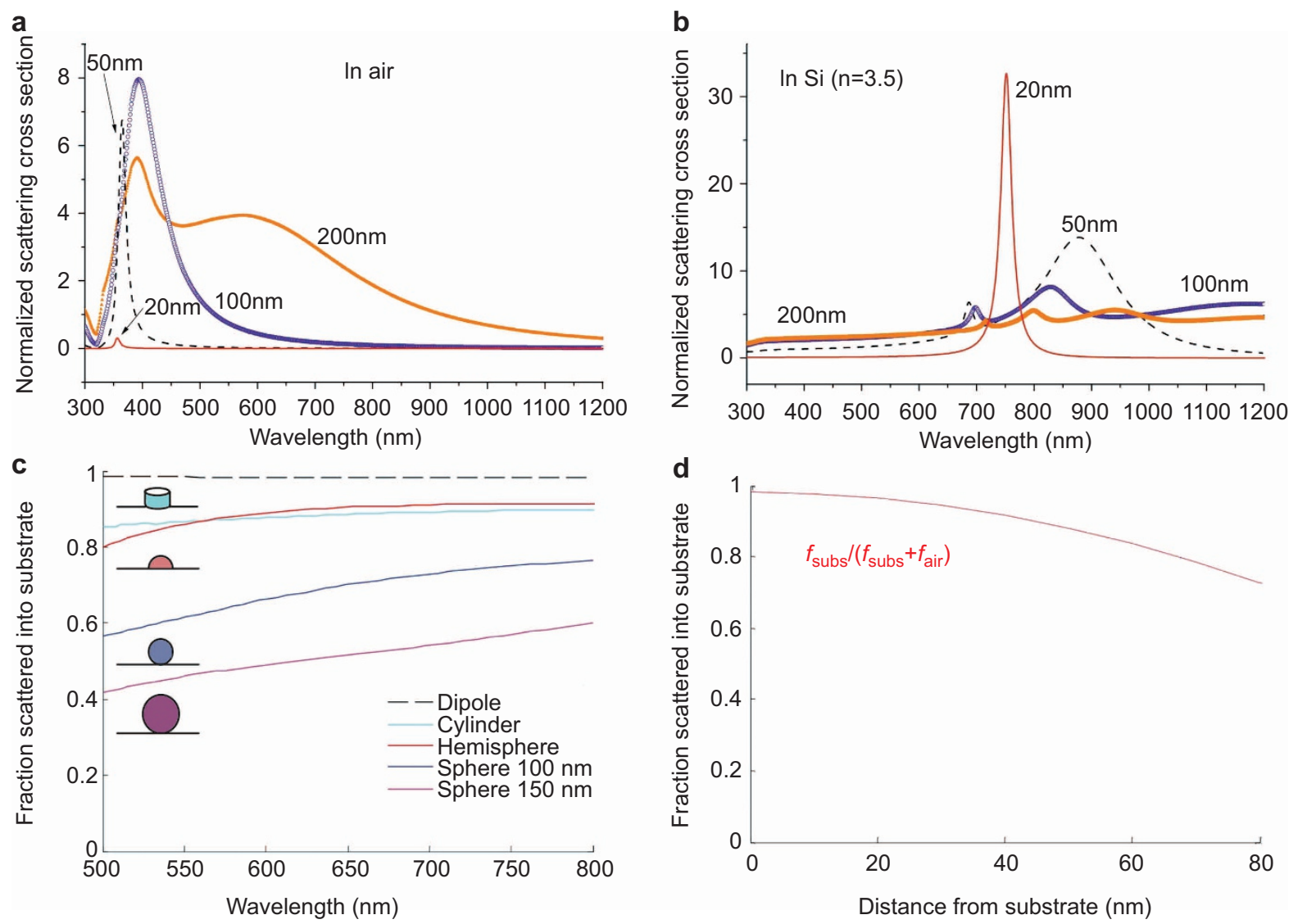

Figure 4 The effect of metallic particle size, shape, distance to substrate and refractive index of medium for nanoparticle scattering. (a, b) Normalized scattering cross sections of Ag nanoparticles in air and Si with various sizes. (c) Fraction of light scattered into the substrate for various sizes and shapes of Ag particles on $\mathrm{Si}$; the dipole is $10 \mathrm{~nm}$ away from Si. (d) Fraction of light scattered into Si as a function of distance for a point dipole above a Si substrate. Figure reproduced with permission: $\mathbf{a}$, b, Ref. 17, (c) 2010 Elsevier; c, Ref. 3, (c) Macmillan Publishers Ltd; d, Ref. 16, (c) 2008 OSA.

with the plasmon near-field coupling of nanoparticles has also been observed in inorganic solar cells including n-CdSe/p-Si heterojunction diodes ${ }^{26}$ and dye-sensitized solar cells. ${ }^{20,27-30}$ In dye-sensitized solar cells, it is also necessary to consider the negative effects (e.g., charging) of the metal nanoparticles in addition to the localized surface plasmon effects. ${ }^{31}$ This field has been quite attractive with the development of synthesis processes of metal nanoparticles and assembly technologies.

Note that for some active materials, the near-field mechanism may not work. For example, a-Si does not benefit from the resonance of Ag nanoparticles due to the mismatch between the bandgap of a-Si and the near-field resonance frequency; for c-Si, the global absorption may not benefit from the local enhanced field due to the weak absorbance of c-Si and the Ohmic loss in the nanoparticles. ${ }^{32}$ Therefore, when utilizing the near-field effect, we must carefully select the materials, metal nanoparticle size, shape, position, etc. to ensure that the enhanced absorption in the active layer can compensate for the accompanying negative effects (e.g., absorption in metal, loss of carrier mobility, increased cost, etc.).

\section{SPPs induced absorption enhancement}

SPPs are plasmon modes that propagate along the metal/dielectric interface. The SPPs can propagate along the interface for a relatively long distance, but are confined to the subwavelength scale in the perpendicular direction. This evanescent wave decay occurs faster in metals than in dielectric materials, which is beneficial for light absorption in active layers. Green et al. ${ }^{33}$ noted that although metal absorption occurs, this process does not fully compromise the benefit of light trapping in the active layer in standard systems, especially organic solar cells. The fabrication of structures with SPPs modes are typically gratings or grooves in the rear contact, and the active layer should directly contact the metallic nanostructures. For example, Ferry et al. ${ }^{34}$ demonstrated that metal contact with a single $100 \mathrm{~nm}$ wide groove covered by a $200 \mathrm{~nm}$ Si thin film can enhance absorption by a factor of 2.5 over a $10 \mu \mathrm{m}$ area for the portion of the solar spectrum near the Si bandgap. When using arrays of Ag nanoridges, a large grating pitch $(6 \mu \mathrm{m})$ results in an enhancement similar to the single ridge case because strong interference does not occur between the SPP waves, whereas a small pitch of $300 \mathrm{~nm}$ leads to a higher absorption enhancement that is more sensitive to wavelength, with narrower spectral features and a wider variation in enhancement across the spectral range. ${ }^{35}$ The largest enhancement could achieve 25 in a narrow wavelength range. SPPs can be excited only for transverse magnetic polarized light incident on the rear gratings and not for transverse electric (TE) polarized incident light. ${ }^{35}$ Wang et al. ${ }^{36}$ demonstrated that a-Si on hybrid gratings of $\mathrm{Ag}$ and indium tin oxide (ITO) exhibits broadband light absorption enhancement, which is related to Fabry-Pérot (F-P) resonance, SPP resonance and planar waveguide coupling. If a thick dielectric spacer layer is placed between the metallic gratings and the active layer, light trapping still occurs, but the enhancement is due to the local and guided modes rather than the SPP modes. ${ }^{37,38}$ Such textured structure with a spacer is also promising; for example, self-cleaning nanodome solar 
cells with a 280 -nm-thick hydrogenated a-Si:H layer can absorb $94 \%$ of the light with wavelengths of $400-800 \mathrm{~nm}$, which is significantly higher than the $65 \%$ absorption of flat film devices. ${ }^{39}$

The enhancement with arrays of ridges is reminiscent of surface wrinkles and folds, ${ }^{40-42}$ which are spontaneously generated by depositing a metallic film on an elastomeric substrate followed by heating. Here, the elastomeric layer can be the organic active materials, and the metallic wrinkles or folds will act as the nanostructured back contact (Figure 5). The folds might be more efficient than wrinkles because the structures are sharper. The grating structures prepared using conventional nanofabrication methods on the back contact help to enhance the absorption; however, this enhancement comes at a price. Surface wrinkling or folding on the back contact might solve this problem for organic solar cells in a cost-effective manner. In addition, organic active materials used in these novel structures yield even better absorption than $\mathrm{Si}$ in the near field. ${ }^{33}$

\section{ABSORPTION BY METAL/INSULATOR/METAL (MIM) MULTILAYERED STRUCTURES}

Another family of important metallic structures for light absorption is MIM multilayered systems. Thanks to the advancement of nanotechnology, especially in nanofabrication, there has recently been significant progress in the development of conventional MIM structures, which offer different fascinating properties. Since the appearance of metamaterials approximately one and half decades ago, metal pattern/ insulator/metal multilayered structures have begun to play an important role in the field.

\section{FP MIM interferometer}

The FP interferometer (etalon) was invented in $1897^{43}$ and typically consists of a transparent plate with two highly-reflecting surfaces (usually made of semitransparent metal), forming a MIM structure. Similar to a conventional ARC, the FP interferometer utilizes the destructive interference between the reflected waves from the air/metal and insulator/metal interfaces. When the thickness of the insulator is
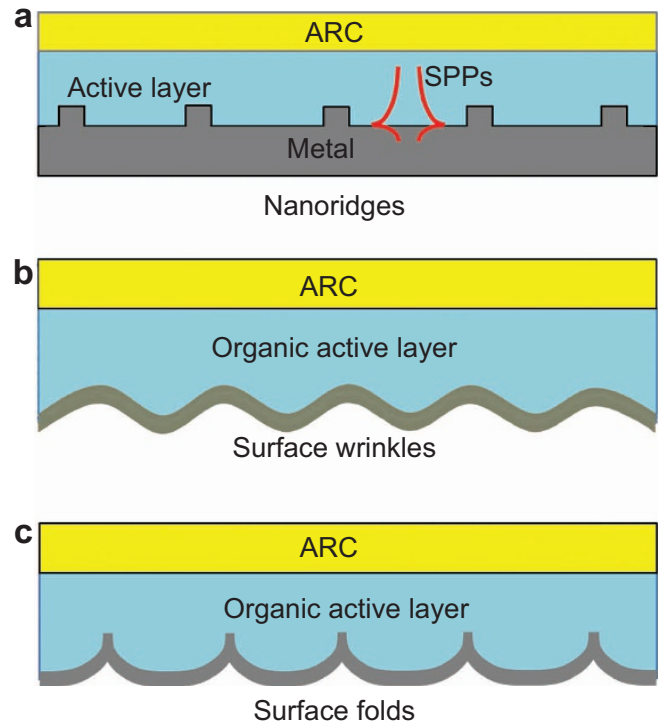

Figure 5 (a) Nanoridges prepared by conventional nanofabrication for light trapping. (b, c) Two proposed structures using spontaneous wrinkling and folding for preparing a patterned back contact. Compared with wrinkles, folds (which are much sharper) may lead to higher enhancement. Wrinkles can convert to folds at large strains. ARC, antireflective coating; SPP, surface plasmonic polariton. odd multiples of $\lambda / 4 n$ ( $\lambda$ is the incident wavelength and $n$ is the refractive index), the beams reflected from the two interfaces have a phase difference of $\pi$. Thus, reflection at $\lambda$ is greatly reduced and transmission is accordingly greatly enhanced. At wavelengths other than $\lambda$, a high reflection can be observed. This type of structure is often referred to as a transmission filter in early papers. ${ }^{44,45}$ One variation of such FP interferometers is the reflection filter: the exit thin metal layer is replaced by an opaque metal mirror (Figure 6). The reflection filter also exhibits a selective reflection property, for which a low reflection at $\lambda$ and high reflection at wavelengths other than $\lambda$ are observed. ${ }^{44,45}$

\section{Metamaterials}

Photonic metamaterials are artificially constructed structures composed of subwavelength building blocks with micro- or nanostructures. The emergence of metamaterials was originally inspired by the discoveries of very low-frequency effective plasmons of thin metallic wire grids ${ }^{46}$ and the effective negative permeability of split ring resonators. ${ }^{47}$ Guided by the theoretical and experimental success of the effective medium theory, ${ }^{48}$ the field has rapidly developed in recent years. Many fascinating optical properties and corresponding devices or structures have been realized, including an invisibility cloak, perfect absorber and superlens. ${ }^{49-51}$ There have been many excellent reviews on the subject, ${ }^{52-55}$ but here we focus only on those related MIM structures.

From the electromagnetic viewpoint, a collection of objects whose size and spacing are much smaller than the wavelength can be described by an effective permittivity $\varepsilon$ and permeability $\mu .{ }^{53}$ One very important family of metamaterials is the MIM structure. ${ }^{50,56,57}$ The schematic unit cells of one such example are presented in the Figure 7. The structure consists of two metallic elements: a top metallic nanopattern and a bottom ground plane, with an insulating dielectric layer as the spacer. The metal patterns are a type of electric ring resonator ${ }^{49,58}$ and couple strongly to uniform electric fields but negligibly to magnetic fields. It was first observed in Ref. 58 that when paired to the dielectric layer and bottom metallic layer, the magnetic component of light couples to both the center section of electric ring resonator patterns and the ground plane, generating antiparallel currents, which results in the resonant response. Thus, by changing only the thickness of the insulating layer, not the geometry of the pattern arrays, the magnetic response $\mu$ can be tuned independent of the electric response $\varepsilon$. When the geometry of the entire system is so tuned that $\varepsilon(\lambda)=\mu(\lambda)$ is satisfied, a high absorption at the wavelength $\lambda$ can be achieved. However, because the electromagnetic response is resonant in a narrow band, broadband application is quite limited. Some attempts were made, most of which were realized by combining several resonances into one desired frequency range or complex pattern designs. ${ }^{59,60}$ For example, Aydin et al. ${ }^{60}$ described an Ag nanopattern $(100 \mathrm{~nm}) / \mathrm{SiO}_{2}$

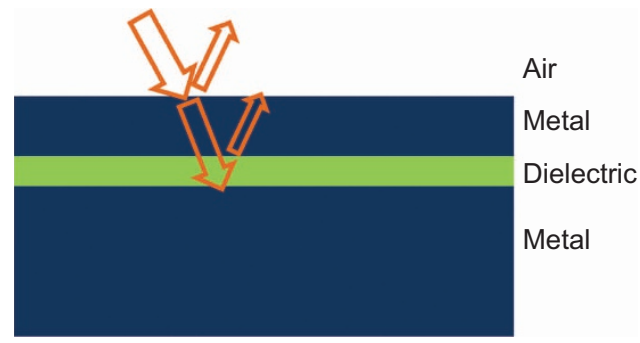

Figure 6 A schematic side view of an MIM structure. MIM, metal/insulator/metal. 

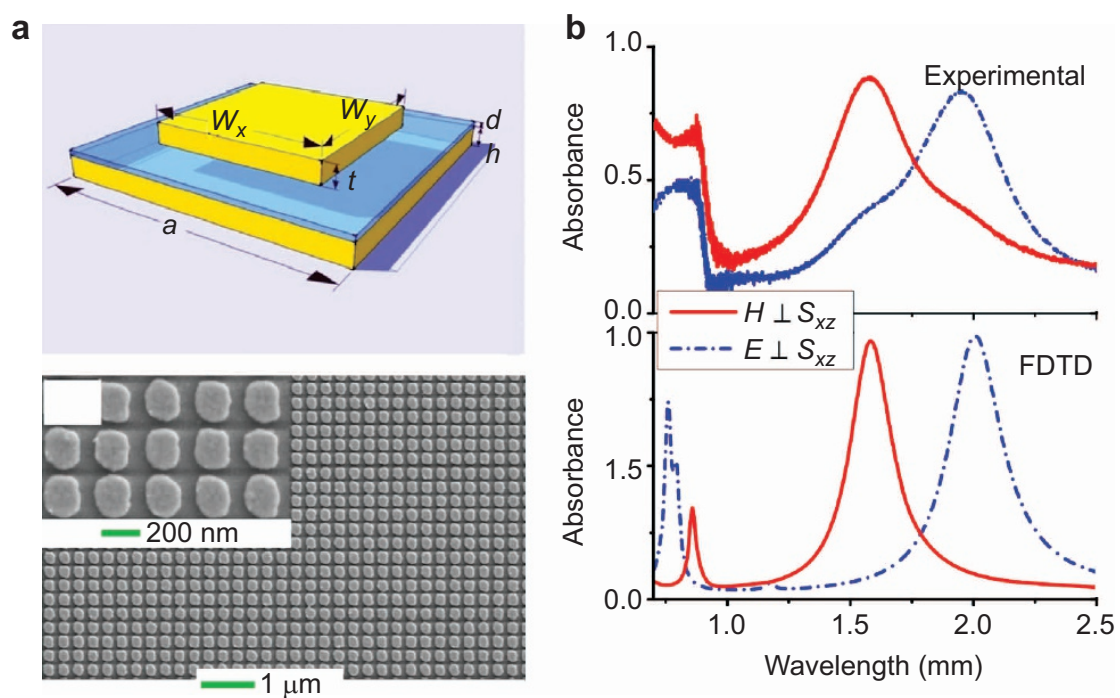

Figure 7 An example of an MIM metamaterial structure. (a) Schematic view and SEM image of the MIM structure and (b) corresponding absorptance. Figure reproduced with permission from Ref. 56, @ 2010 AIP. FDTD, finite difference time domain; MIM, metal/insulator/metal; SEM, scanning electron microscopy.

$(60 \mathrm{~nm}) / \mathrm{Ag}$ film $(100 \mathrm{~nm})$ super absorber that exhibits an average absorbance of $71 \%$ over the entire visible spectrum.

The application of these MIM types of metamaterials is closely related to the development of nanofabrication techniques and advances of computational simulation. With the first demonstrations being realized in the range from microwaves to the far IR in the early $2000 \mathrm{~s},{ }^{61,62}$ applications in visible and even close ultraviolet range have been easy to find in recent years. ${ }^{63,64}$

\section{Absorptive material as the insulator}

Both F-P MIM systems and the metamaterial MIM systems mentioned above can function as a single frequency absorber. However, there is vital difference between the two mechanisms: absorption in the F-P MIM system is based on phase accumulation, requiring a dielectric spacer on the order of $\lambda / 4 n$; metamaterials, however, are based on electromagnetic resonance, requiring a thickness of the dielectric layer $d<<\lambda$. How to narrow this scale gap and bring the two systems together is an interesting topic. In one recent scheme, it was demonstrated that if a high index absorptive material is incorporated into the structure, enhanced absorption can be achieved with a broad bandwidth. ${ }^{65-67}$

As described in a classic optics book, ${ }^{68}$ the reflected electrical components from an insulator/metal system can be expressed by the Fresnel coefficients of corresponding interfaces: if only the first two partial waves reflected back into air are considered, $\tilde{r}_{i}=\frac{1-\tilde{n}_{i}}{1+\tilde{n}_{i}}$ represents the Fresnel coefficient of the air/insulator interface and $\tilde{r}_{i / m}=\frac{\tilde{n}_{i}-\tilde{n}_{m}}{\tilde{n}_{i}+\tilde{n}_{m}}$ represents that of the insulator/metal interface $\left(\tilde{n}_{i}\right.$ and $\tilde{n}_{m}$ are the complex refractive indices of the insulator and the metal). The combined reflected wave is

$$
\tilde{r}=\frac{\tilde{r}_{i}+\tilde{r}_{i / m} e^{i 2 \theta}}{1+\tilde{r}_{i} \tilde{r}_{i / m} e^{i 2 \theta}}
$$

where $\theta=2 \pi / n_{i} \lambda$ is the single-trip phase change in the dielectric layer. Thus, the reflectance $R$ in terms of energy is $|\tilde{r}|^{2}$. Using simple algebra, to achieve the lowest reflection $(r=0)$ in air, one needs $\tilde{r}_{i}=-\tilde{r}_{i / m} e^{i 2 \theta}$. Recently, it was specifically noted in Ref. 66 that if the dielectric medium is absorptive, $\tilde{r}_{i}$ and $\tilde{r}_{i / m}$ are no longer real numbers and consist of phase factors. Most importantly, from the definition of Fresnel coefficients, it can be observed that the phases of $\tilde{r}_{i}$ and $\tilde{r}_{i / m}$ are not limited to 0 or $\pi$, but depend on that of different $\tilde{n}_{i}$. Under such circumstances, it is possible that $\tilde{r}_{i}=-\tilde{r}_{i / m} e^{i 2 \theta}$ can be satisfied at a thickness of $d \neq \lambda / 4 n_{i}$ $(2 \theta \neq \pi)$. In extreme cases, if $\tilde{r}_{i}$ and $\tilde{r}_{i / m}$ are already out of phase, to satisfy the low reflection condition, $d$ could be much smaller than $\lambda$. As described in Ref. 66, to achieve a low reflection of approximately $20 \%$ at $500 \mathrm{~nm}$, only $8 \mathrm{~nm}$ Ge is required on a Au film. Such ultrathin structures with high absorptance are mostly desired for photovoltaic applications.

Dielectric/perforated metal film/insulator/metal (DPIM) structures In conventional F-P MIM filters, the spacer is usually a lossless dielectric layer. By replacing the lossless material with an absorptive material, such as amorphous silicon in the visible range, a similar effect can be observed: the resonance occurs at a thickness much smaller than the wavelength. This effect helps narrow the scale gap between the metamaterial MIM scheme and the F-P MIM scheme. ${ }^{65}$ Wang et al. ${ }^{65}$ demonstrated that a perforated metal film/absorptive insulator/metal (PIM) structure satisfies the MIM interference requirements discussed above. In this structure, the a-Si film is only $15 \mathrm{~nm}$ thick, and the top Ag checkerboard covers $\sim 50 \%$ of the a-Si surface. Such a PIM multilayer system made of a nanoscopically perforated metallic film and an ultrathin absorber formed a metamaterial effective medium that exhibits negative refraction in the frequency range of interest. If such a planar PIM structure is further capped with a dielectric interference film to tune the phase difference between waves reflected from the top and bottom surfaces of the PIM structure, the structure can highly absorb electromagnetic radiation in the entire visible range, as shown in Figure 8. The absorptance of this structure is sensitive to the thickness of a-Si, but insensitive to the period or feature size of the metallic nanostructures. The introduction of the self-complementary pattern removes the electrical resonance in the interested range. The same effect was also observed in aperiodic perforated metallic films (e.g., aperiodic structures in Refs. 69, 70), in which unlike plasmonic structures, no dependence of periodicity is even required. Simulations were performed to demonstrate this idea. A 12-nm-thick a-Si on 60-nm Ag structure capped with a layer of random metallic nanomesh followed by a 60 -nm-thick $\mathrm{SiO}_{2}$ film exhibits quite good absorptance (Figure 8), 


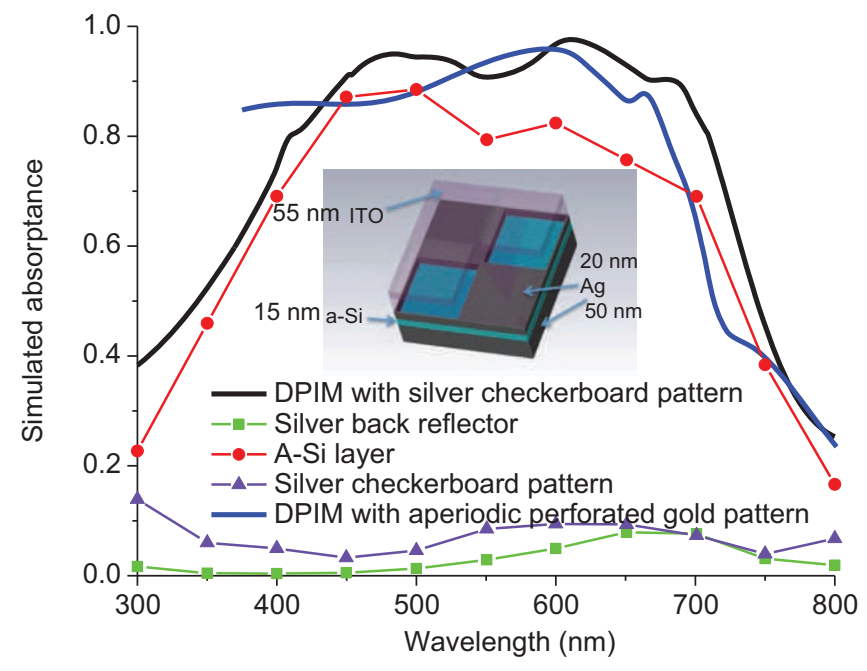

Figure 8 Absorptance of DPIM structure with periodic and aperiodic structures. A schematic view of the DPIM structure is shown in the inset. A-Si, amorphous silicon; DPIM, dielectric/perforated meta film/insulator/metal structures.

quite close to the result with a periodic structure. This result confirms that the broadband absorption feature does not depend on specific perforation geometry, or even aperiodicity; thus, it is possible to fabricate highly absorbed PIM structures with simple and cost-effective nanofabrication methods.

Compared with the nanoparticle plasmonic photovoltaic structures, the dielectric/perforated meta film/insulator/metal (DPIM) structures have an ultrathin a-Si layer of $\sim 10 \mathrm{~nm}$ thick, together with two metal surfaces, and thus are more likely to be used in ultrathin solar cells. The perforated top patterns can be used as the front contact with good flexibility and good electrical conductivity; ${ }^{70-72}$ therefore, the DPIM structure is potentially a good selection for flexible solar cells.

\section{METALLIC NANOSTRUCTURE-ENABLED SELECTIVE SOLAR ABSORBER}

Although much less attention is paid to solar thermal conversion processes than photovoltaics, these processes are actually a major route for harvesting solar radiation by converting sunlight directly to heat with the use of spectrally selective solar absorbers. The generated heat can further be converted into electricity. The sunlight can be concentrated to get a higher temperature and thereby a higher efficiency, known as concentrated solar power (CSP) plant technology. There is $\sim 300 \mathrm{GW}$ of installed solar hot water system and $\sim 3$ GW of CSP plant worldwide $\mathrm{e}^{2,73}$ which is much larger than the installed capacity of solar photovoltaic cells. New technologies of solar thermoelectric generators and solar thermophotovoltaics for CSP plants are currently being researched, but are not yet commercialized. ${ }^{74}$ A selective solar absorber that meets the requirements of the CSP program should have an absorptance of at least 0.95 and an emittance of less than 0.10 at $400{ }^{\circ} \mathrm{C} .{ }^{75}$

The photothermal conversion efficiency can be determined by the solar selectivity of the solar selective absorber, which is determined by the absorptance $\left(\alpha_{s}\right)$ and emittance $\left(\varepsilon_{t}\right)$ of spectrally selective coatings based on the following equations: ${ }^{76}$

$$
\alpha_{s}(\theta)=\frac{\int_{\lambda_{\min }=0}^{\lambda_{\max }=\infty}\{[1-\rho(\lambda, \theta)] S(\lambda)\} \mathrm{d} \lambda}{\int_{\lambda_{\min }=0}^{\lambda_{\max }=\infty} S(\lambda) \mathrm{d} \lambda}
$$

$$
\varepsilon_{t}(\theta, T)=\frac{\int_{\lambda_{\min }=0}^{\lambda_{\max }=\infty}\{[1-\rho(\lambda, \theta)] B(\lambda, T)\} \mathrm{d} \lambda}{\int_{\lambda_{\min }=0}^{\lambda_{\max }=\infty} B(\lambda, T) \mathrm{d} \lambda}
$$

where $\lambda$ is the wavelength, $\rho(\lambda, \theta)$ is the angular dependent (incident angle $\theta$ ) spectral reflectance, $S(\lambda)$ is the direct normal solar irradiance (AM 1.5), $B(\lambda, T)$ is the blackbody spectral radiation and $T$ is the absolute temperature.

Solar water heater systems that apply a solar absorber to heat water have been widely used in China and Europe. Such systems can be highly efficient; for example, a commercial evacuated tube collector can achieve an efficiency of $\sim 80 \%$. However, for electricity generation, the efficiency is much lower. A recent advance in solar thermoelectric generators, in which a selective solar absorber absorbed light and generated heat, while a pair of thermoelectric elements connected to the solar absorber were used to convert the thermal energy to electricity (Figure 9), presented a peak efficiency of $4.6 \%$ under AM $1.5 \mathrm{G}$ condition. ${ }^{74} \mathrm{New}$ designs of a CSP system might further enhance the entire conversion efficiency to $10 \%$, which is comparable to a-Si:H cells, with the greatest advantage being that such a system could provide electricity around the clock by storing the heat, eliminating the need of a battery for electricity storage. However, improving the efficiency requires a large temperature difference between the two ends of the thermoelectric elements. A recent study reported that at an emittance of 0.05 and a solar concentration 10 times the AM 1.5G spectrum, the optimal transition wavelength is observed to be $1.28 \mu \mathrm{m}$ and have a $957 \mathrm{~K}$ equilibrium temperature. ${ }^{77}$ Therefore, good thermal stability at high temperatures is required.

The high absorptance and low emittance can result in a high photothermal conversion efficiency of solar selective coatings. An ideal solar absorber should have zero reflectance over the solar spectrum and zero emittance in the middle IR region (Figure 10), which allows complete absorption of solar energy without thermal radiation. However, in reality, such an absorber does not exist; absorbers with 95\% absorption and 5\% emittance are realistic. The first practically useful coatings were proposed by Tabor in $1955 .^{78}$ Then, various spectrally selective surfaces, such as black chrome coatings, $\mathrm{Ni}-\mathrm{Al}_{2} \mathrm{O}_{3}$ cermet-based surfaces, $\mathrm{Cr} / \mathrm{Cr}_{x} \mathrm{O}_{y} / \mathrm{Cr}_{2} \mathrm{O}_{3}$ multilayer absorber coatings and paints including organic black carbon and inorganic pigment $\mathrm{FeMnCuO}_{x}$, were extensively investigated. ${ }^{78-84}$ According to the film configuration and absorption mechanism, solar absorbers can be categorized into six types. ${ }^{75}$ Among these types, most of the practically useful absorbers, including multilayer absorbers, cermet-based absorbers and textured surfaces, have metallic nanostructures. The metal component, particle size, orientation, coating thickness and metal volume fraction in the matrix have a strong effect on the solar selectivity.

In solar selective coatings with metallic nanostructures, metals play an important role. First, a thick bottom metal layer is used as an IR reflector due to its low emissivity in the mid- and far-IR range and its high thermal conductivity. Most of the commercialized spectrally selective coatings are supported on copper or aluminum substrates to maximize the photothermal conversion efficiency. In addition to the thick metal layer, metallic nanostructures, such as thin metal films, metal nanoparticles and metal islands, are often employed in solar selective surfaces. The thin metal film (several nanometers) is used as a semitransparent reflective layer in multilayer absorbers. The metal nanoparticles embedded in a dielectric matrix are used to adjust the optical properties of the cermet layer. Metallic nanostructures, however, may cause some durability problems at high temperature. Here, we focus only on multilayer absorbers and cermet-based absorbers to 
a

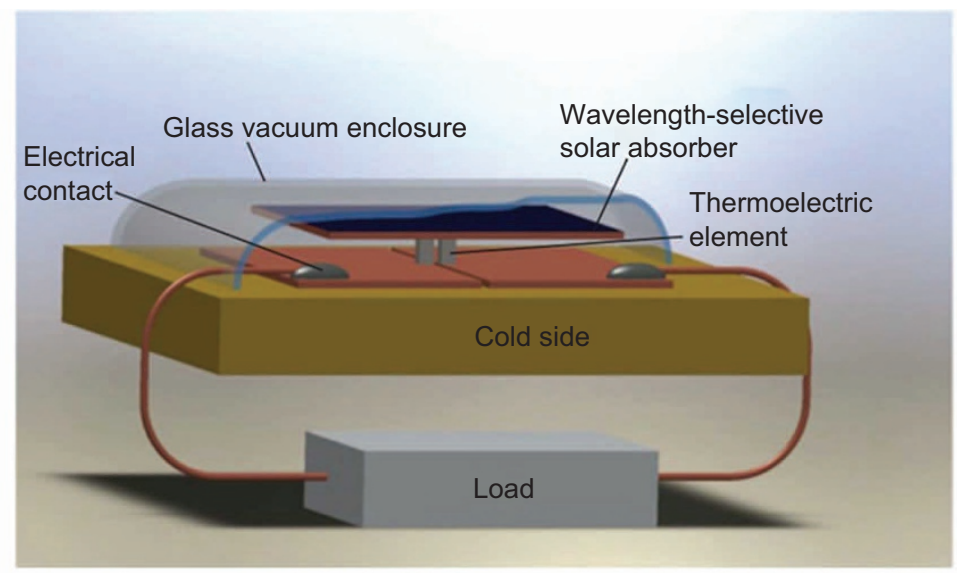

b

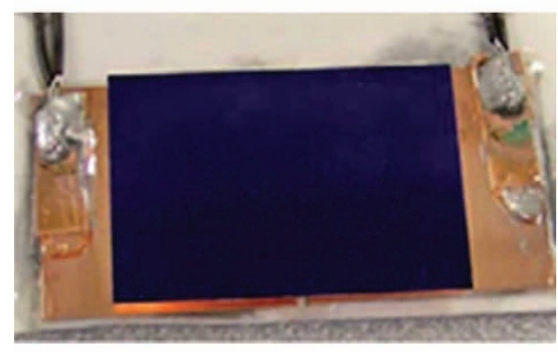

c

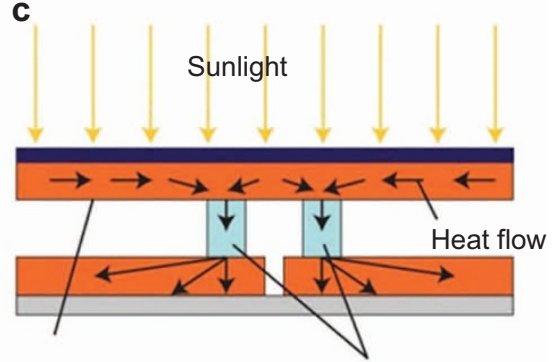

Solar absorber/ thermal concentrator
Thermoelectric elements

Figure 9 (a) The structure of a solar thermoelectric generator consisting of a pair of $\mathrm{p}$ - and $\mathrm{n}$-type thermoelectric elements, a flat-panel selective absorber that also acts as a thermal concentrator. The device is surrounded by a glass enclosure that maintains an evacuated environment. (b) Optical image of the solar absorber used in the device. (c) Illustration of thermal concentration. Figure reproduced with permission: Ref. 74, @ 2011 Macmillan Publishers Ltd.

discuss the function of metallic nanostructures in multilayer and cermet coating solar absorbers using several examples.

\section{Multilayer absorbers}

Multilayer absorbers consist of alternating metal and dielectric layers. The absorption mechanism of multilayer absorbers uses the multiple reflections at the layer interfaces. A bottom semitransparent metal layer (D) serves as a reflective layer that separates the two quarterwave dielectric layers. This layer has high reflectance in the IR region

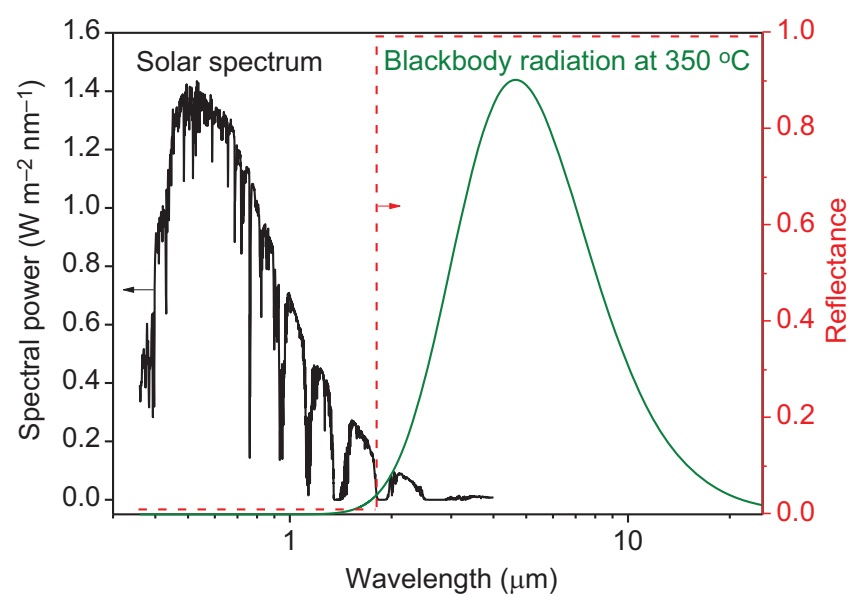

Figure 10 An ideal solar absorber with a sharp reflectance increasing from 0 to 1 at $\sim 1.8 \mu \mathrm{m}$. and is slightly less reflective in the visible region. The top dielectric layer (C) acts as an ACR for the metal layer (D) and reduces the visible reflectance. The thickness of this dielectric layer determines the shape and position of the reflectance curve. Another dielectric/metal (A/B) bilayer further reduces the reflectance in the visible region and broadens the absorption region (Figure 11a). ${ }^{75}$ The thickness of the dielectric layer has a large effect on the solar selectivity. The stability of this type of solar absorber strongly depends on the materials used. Metallic nanofilms with high melting points, high nitriding or oxidation resistance and low diffusion are promising candidates.

The thermal emission of a one-dimensional metallodielectric periodic structure was analyzed by Narayanaswamy and Chen. ${ }^{85}$ Their simulation indicated that the emissivity of the periodic structure consisting of 11 unit cells with $10 \mathrm{~nm}$ silver and $150 \mathrm{~nm}$ of vacuum in the IR range could be reduced by more than two orders of magnitude compared with that of a bare 10-nm silver film. Several multilayer absorbers based on different metallic nanofilms (Al, Pt, Cr, Ti) and
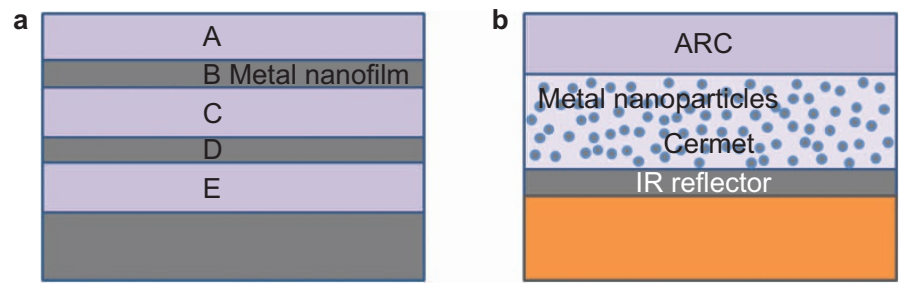

Figure 11 Two types of spectrally selective solar absorbers with metallic nanostructures. (a) Multilayered absorber. (b) Cermet solar absorber. ARC, antireflective coating; IR, infrared. 
dielectric layers $\left(\mathrm{Al}_{2} \mathrm{O}_{3}, \mathrm{AlN}, \mathrm{Cr}_{2} \mathrm{O}_{3}, \mathrm{SiO}_{2}\right)$ were developed for solar thermal conversion application. In 2009, Barshilia demonstrated that $\mathrm{Al}_{x} \mathrm{O}_{y} / \mathrm{Al} / \mathrm{Al}_{x} \mathrm{O}_{y}$ multilayer absorbers exhibit a high absorptance of $0.95-0.97$ and a low emittance ranging from 0.06 to 0.08 at $82{ }^{\circ} \mathrm{C} .{ }^{86}$ This coating on a Cu substrate was stable at up to $400{ }^{\circ} \mathrm{C}$ in air, and degradation occurred when the temperature exceeded $450{ }^{\circ} \mathrm{C}$ due to the diffusion of $\mathrm{Cu}$. Replacing $\mathrm{Cu}$ with a Mo substrate, the solar absorber was stable up to $450{ }^{\circ} \mathrm{C}$ in air and $800{ }^{\circ} \mathrm{C}$ in vacuum. ${ }^{86}$ Other systems such as $\mathrm{Al}_{x} \mathrm{O}_{y} / \mathrm{Pt} / \mathrm{Al}_{x} \mathrm{O}_{y},{ }^{87} \mathrm{SiO}_{2} / \mathrm{Ti} / \mathrm{SiO}_{2} / \mathrm{Al},{ }^{88} \mathrm{AlN} / \mathrm{Ti} /$ $\mathrm{AlN},{ }^{89}$ and $\mathrm{HfO}_{x} / \mathrm{Mo} / \mathrm{HfO}_{2}$ were also investigated. ${ }^{90}$ The colored solar selective coatings in the Ti/AlN multilayer structure were obtained by adjusting the layer number and thickness. ${ }^{89}$ The prepared surfaces display black, purple, yellowish green, red and yellowish orange, among which the purple surface exhibited the best solar selectivity, with a high absorptance of 0.94 and a low emittance of $0.05 .{ }^{89}$ Commercial solar absorbers often display a purple or blue color instead of black; we should consider the light trapping not only in the visible region, but in the entire solar spectrum as well as emission in the IR region. $\mathrm{HfO}_{2}$ is a dielectric material with a high reflective index, wide bandgap $(5.5 \mathrm{eV})$ and good mechanical, chemical and thermal stability. The $\mathrm{HfO}_{x} / \mathrm{Mo} / \mathrm{HfO}_{2}$ system can be stable up to $500{ }^{\circ} \mathrm{C}$ in air. The $\mathrm{HfO}_{2}$ layer acted as an antireflection layer, and light was largely absorbed in the $\mathrm{HfO}_{x}$ and Mo layers. The addition of a Mo layer between the $\mathrm{Cu}$ substrate and the $\mathrm{HfO}_{x}$ layer could suppress the diffusion of $\mathrm{Cu}$ and thereby enhance the thermal stability. ${ }^{90}$

\section{Cermet-based solar absorbers}

Cermet is a metal-dielectric composite in which metal nanoparticles are imbedded in the dielectric matrix. The coatings strongly absorb solar light due to inter-band transitions in the metal in combination with small particle resonance, while the coatings are almost transparent in the IR region. ${ }^{75}$ The low emission mainly stems from the metal substrate, and the high absorbance is related to the cermet coating and the ARC. To date, cermet coatings have been extensively investigated for mid- and high-temperature solar thermal applications due to their high absorptance in a large solar region, low emittance in the IR region and good thermal stability. The solar selectivity of cermet-based solar absorbers can be affected by the coating thickness, metal volume fraction in the composites and particle size, shape and orientation. A typical and simple configuration comprises a metal layer for the IR reflector, a cermet layer and an antireflection coating, as illustrated in Figure $11 \mathrm{~b}$. The absorbing cermet coating may have an inherently high-temperature material layer of either a uniform or graded metal content or double layers with different metal contents.

An early commercialized cermet solar absorber, black chrome $(\mathrm{Cr}-$ $\mathrm{Cr}_{2} \mathrm{O}_{3}$ ) prepared by electroplating demonstrated a solar selectivity (ratio of absorptance to emittance) of $9.18 .{ }^{84}$ When the annealing temperature increased to $400{ }^{\circ} \mathrm{C}$, the amorphous $\mathrm{Cr}_{2} \mathrm{O}_{3}$ phase became crystallized, and the phase further evolved to $\mathrm{Cr}_{3} \mathrm{O}_{4}$ as the temperature increased to $500{ }^{\circ} \mathrm{C} .{ }^{91}$ Optimized coatings exhibited long-term stability, with the samples remaining stable after years of operation at $300{ }^{\circ} \mathrm{C}$ in air. The graded $\mathrm{Cr}-\mathrm{Cr}_{2} \mathrm{O}_{3}$ layers on $\mathrm{Cu}$ substrates exhibited a higher absorptance in the range of 0.90-0.94 and a lower emittance of $0.04 .^{80} \mathrm{Al}_{2} \mathrm{O}_{3}$ was then widely used as the dielectric material because of its high thermal and chemical stability. Sputtered $\mathrm{Ni}-\mathrm{Al}_{2} \mathrm{O}_{3}$ selective coatings were extensively investigated for mid- and high-temperature applications. $\mathrm{Ni}-\mathrm{Al}_{2} \mathrm{O}_{3}$ cermet-based solar selective surfaces were also prepared using other methods including dual-electron-beam evaporation and a solution-chemical method. ${ }^{83,92}$ The solar selectivity of $\mathrm{Ni}-\mathrm{Al}_{2} \mathrm{O}_{3}$ coatings was further improved by adding an $\mathrm{ARC}$, and the solar absorptance was increased while keeping the thermal emittance unchanged. ${ }^{93}$ Other metals such as $\mathrm{Co}, \mathrm{Ti}, \mathrm{Mo}, \mathrm{W}$ and Pt were also used as the metal component in $\mathrm{Al}_{2} \mathrm{O}_{3}$-based cermet. Although the $\mathrm{Mo}-\mathrm{Al}_{2} \mathrm{O}_{3}$ and $\mathrm{W}-\mathrm{Al}_{2} \mathrm{O}_{3}$ cermets were expected to be suitable for high-temperature application, difficulties still occurred because diffusion or a phase change of the metallic nanoparticles at high temperature results in degradation of the coatings. ${ }^{94,95}$

Double-layered coatings were also developed. In a double-layered cermet film, solar radiation is absorbed internally through phase interference in double-cermet solar coatings. Simulations indicated that the double layer cermet film exhibits a higher conversion efficiency compared with the uniform cermet or graded cermet film. ${ }^{96}$ The double-cermet layer structure consisting of a AlN top layer, a cermet layer with a low metal volume fraction, and another cermet layer with a high metal volume fraction exhibited a high solar absorptance of 0.953 and a near-normal emittance of 0.051 for W-AlN cermet ${ }^{97}$ and 0.933 and 0.025 , respectively, for SS-AIN cermet. ${ }^{98}$ The W- and SSAlN cermet films offer the advantage of the high reactivity of aluminum with nitrogen. ${ }^{97,98}$ The coatings with double absorption layers of high metal volume fraction and low metal volume fraction prepared by co-evaporation exhibited a high absorptance of 0.911 and a low emittance of 0.0196 at $50{ }^{\circ} \mathrm{C} .{ }^{99}$ Double-layered cermet films are also stable. For a SS-AIN cermet structure, only a small change was observed in the reflectance spectra after heating at $500{ }^{\circ} \mathrm{C}$ for 1 h. ${ }^{98}$

Generally, cermet-based solar absorbers exhibit good overall performances of high absorptance, low emittance, and good thermal stability and, therefore, have been used in CSP systems. ${ }^{75}$ Compared with multilayer solar absorbers, cermet coatings may be prepared using costeffective chemical solution approaches, although vacuum deposition such as sputtering remains the mainstream preparation method.

\section{Novel design of solar absorbers}

Very recently, a work on a solution-processed plasmonic Ni nanochain$\mathrm{Al}_{2} \mathrm{O}_{3}$ cermet coating (Figure 12) revealed that unlike conventional multilayer graded-index cermet coatings, the SPP-enhanced solar absorption in these nanostructures is tailored by the lengths of the Ni nanochains instead of the cermet layer thicknesses, thus eliminating the requirement of costly vacuum deposition for stringent thickness control. ${ }^{100}$ This cermet coating exhibited an absorption of $>0.9$ and an emittance of $<0.1$.

In Figure 13, we propose a new structure of a selective solar absorber. The structure consists of a top metallic nanofilter, a middle absorbing layer, and a bottom metal substrate. The mesh size of the metallic nanofilter, $w$, can be optimized such that it is highly transparent in the region where the absorbing layer works well (visible and near-IR region) but highly reflective to light with a wavelength much larger than the mesh size (e.g., IR light $>2 \mu \mathrm{m}) .{ }^{101,102}$ With the development of nanotechnology, the top metal network structures are already available in a cost-effective manner, ${ }^{69,103}$ while the middle absorbing layer can be sprayed graphite or other inexpensive materials with a modest thickness. Without a top metallic nanofilter, the emittance of the structure may reach a considerably high level, and hence, the photo-thermal conversion efficiency is low.

\section{CONCLUSIONS AND OUTLOOK}

This article reviewed the applications of metallic nanostructures for light trapping in solar energy-harvesting structures and devices from thin film photovoltaic cells to solar thermal structures and devices. The light trapping effect with metallic nanoparticles in photovoltaic devices can stem from far-field scattering or from strong near-field scattering surrounding the metallic particles. The coupling of light 


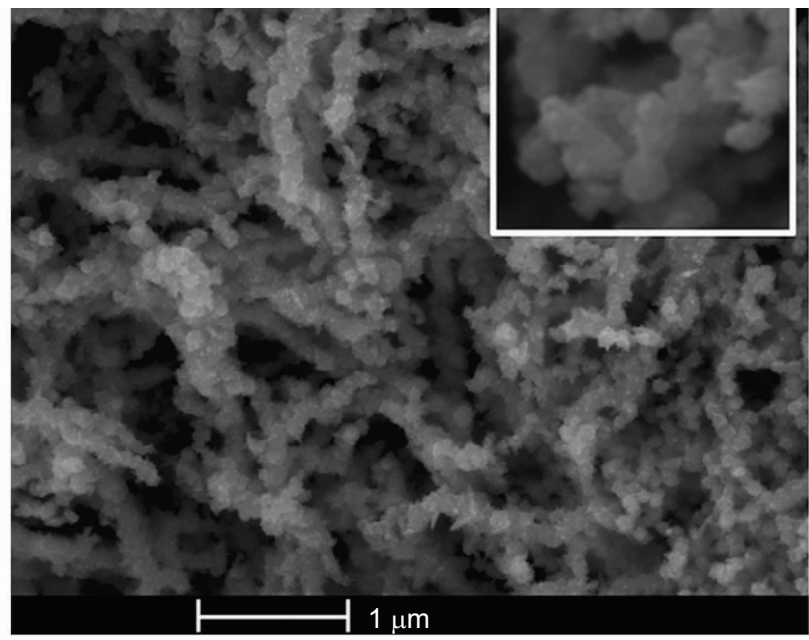

b

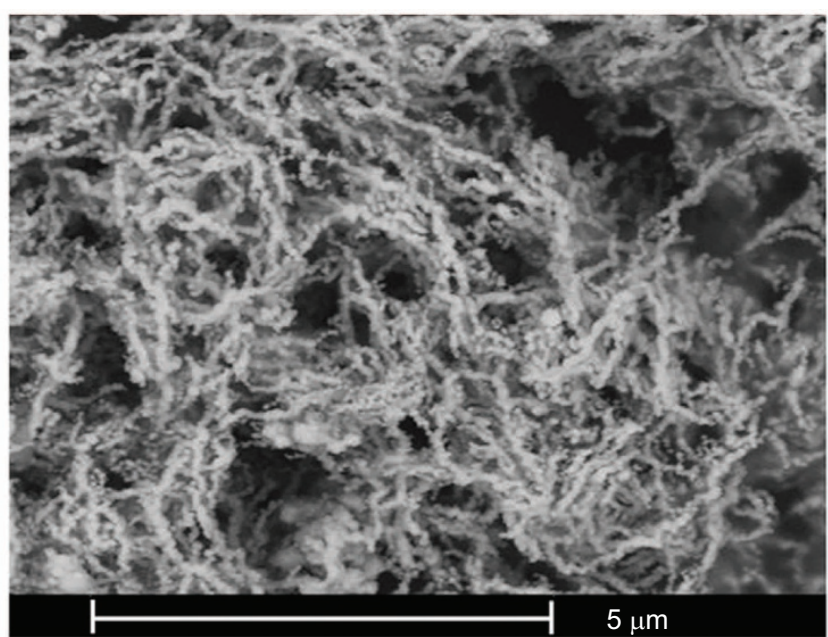

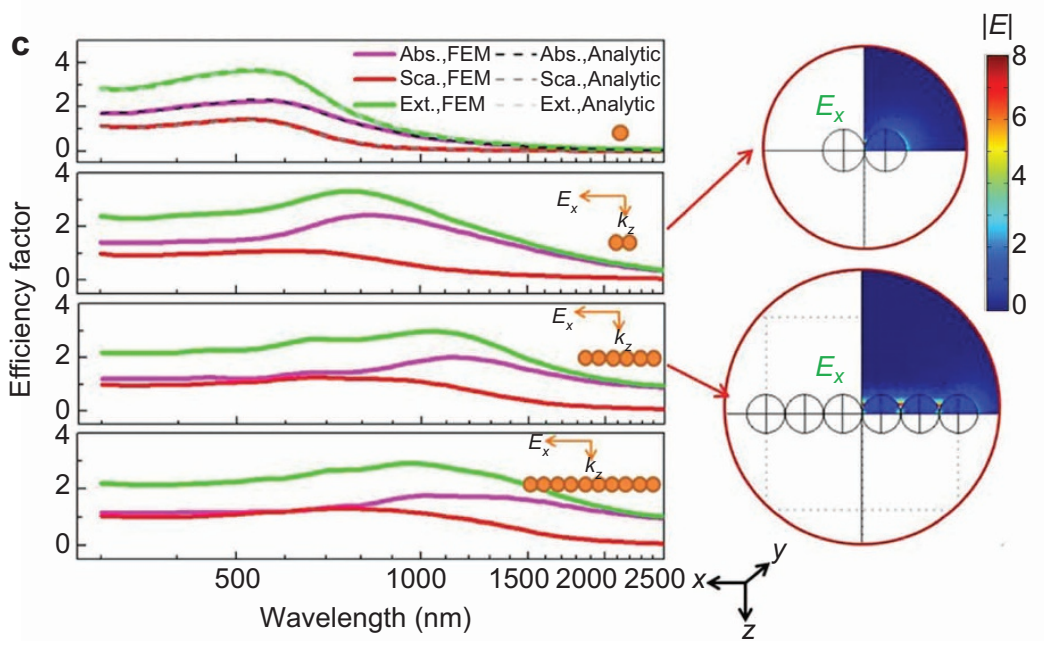

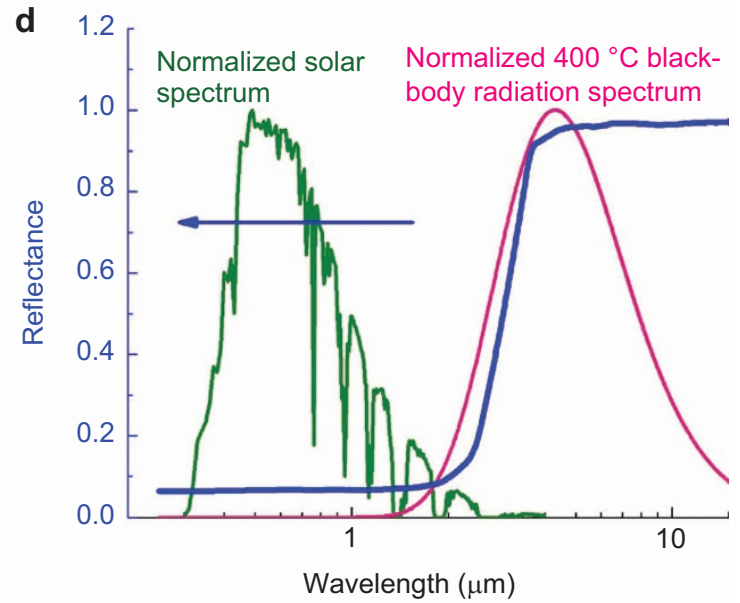

Figure 12 (a, b) SEM images of as-synthesized and annealed Ni nanochain- $\mathrm{Al}_{2} \mathrm{O}_{3}$ composites. (c) 3D finite-element calculation along the chain direction of absorption (magenta line), scattering (red line) and extinction (green line) efficiency factors vs. wavelengths for individual Ni nanochains with 1, 2, 6 and 10 nanospheres. (d) The reflectance of the Ni nanochain- $\mathrm{Al}_{2} \mathrm{O}_{3}$ cermet spectrally selective film. The normalized solar spectrum and $400{ }^{\circ} \mathrm{C}$ black body radiation are also shown for reference. Figure reproduced with permission from Ref. 100, @ 2012 AIP. Abs, absorption; 3D, three-dimensional; Ext, extinction; FEM, finite-element method; Sca, scattering; SEM, scanning electron microscopy.

into the SPP mode can significantly enhance light absorption in the long wavelength region near the back contact. These structures can significantly decrease the thickness of the active layer. The MIM structure, a structure with a top metallic nanopattern and a thin dielectric on a metal substrate, is especially suitable for ultrathin photovoltaic devices, for which light can be highly absorbed in an $\sim 10 \mathrm{~nm}$ thick active layer. Such ultrathin structures not only offer high efficiency and low cost, but can also potentially be used as flexible solar cells.
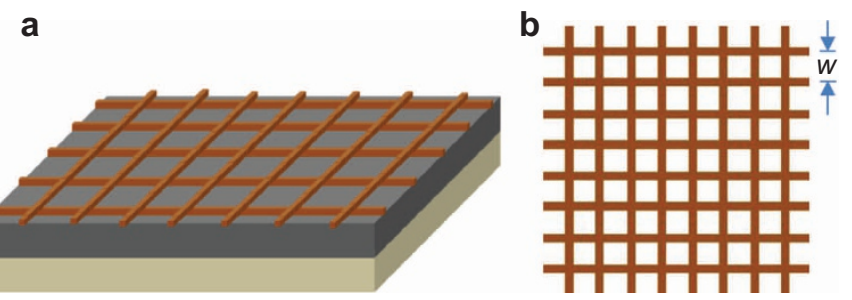

Figure 13 (a) A schematic illustration of a metallic nanofilter/absorbing layer/ metal substrate selective absorber. (b) Top view of the metallic nanofilter with a mesh size of $w$.
We also briefly discussed metallic nanostructures in solar absorbers, which are used for converting solar energy into heat and potentially for further converting this heat into electricity. Such solar absorbers require both high photo-thermal conversion efficiency and good durability at high temperature for CSP systems. We also proposed a novel metallic filter nanostructure that may significantly simplify the process of fabrication of solar absorbers and decrease the cost.

\section{ACKNOWLEDGMENTS}

The work performed at the University of Houston was funded by the US Department of Energy under contract number DOE DE-FG02-13ER46917/DESC0010831, and the work performed at the National Center for Nanoscience \& Technology of China was supported by the funds of NSFC (10974037), NBRPC (2010CB934102), International S\&T Cooperation Program (2010DFA51970) and the 'Strategic Priority Research Program' of the Chinese Academy of Sciences (Grant No. XDA09020300).

Abbott D. Keeping the energy debate clean: how do we supply the world's energy needs? Proc IEEE 2010; 98: 42-66. 
2 Weiss W, Mauthner F. International energy agency 2010, http://www.iea-shc.org

3 Atwater HA, Polman A. Plasmonics for improved photovoltaic devices. Nat Mate 2010; 9: 205-213.

4 Green MA, Emery K, Hishikawa Y, Warta W, Dunlop ED. Solar cell efficiency tables (version 39). Prog Photovoltaics 2012; 20: 12-20.

5 Zhao J, Wang A, Green MA, Ferrazza F. 19.8\% efficient "honeycomb" textured multicrystalline and $24.4 \%$ monocrystalline silicon solar cells. App/ Phys Let 1998; 73: 1991-1993.

6 Li T, Suo Z, Lacour SP, Wagner S. Compliant thin film patterns of stiff materials as platforms for stretchable electronics. J Mater Res 2005; 20: 3274-3277.

7 Lipomi DJ, Tee BC, Vosgueritchian M, Bao Z. Stretchable organic solar cells. Adv Mater 2011; 23: 1771-1775.

8 Spinelli P, Ferry VE, van de Groep J, van Lare M, Verschuuren MA et al. Plasmonic light trapping in thin-film Si solar cells. J Opt 2012; 14: 024002.

9 Schaadt DM, Feng B, Yu ET. Enhanced semiconductor optical absorption via surface plasmon excitation in metal nanoparticles. Appl Phys Lett 2005; 86: 063106.

10 Stuart HR, Hall DG. Island size effects in nanoparticle-enhanced photodetectors. App Phys Lett 1998; 73: 3815-3817.

11 Derkacs D, Lim SH, Matheu P, Mar W, Yu ET. Improved performance of amorphous silicon solar cells via scattering from surface plasmon polaritons in nearby metallic nanoparticles. Appl Phys Lett 2006; 89: 093103.

12 Pillai S, Catchpole KR, Trupke T, Green MA. Surface plasmon enhanced silicon solar cells. J Appl Phys 2007; 101: 093105.

13 Nakayama K, Tanabe K, Atwater HA. Plasmonic nanoparticle enhanced light absorption in GaAs solar cells. Appl Phys Lett 2008; 93: 121904

14 Mokkapati S, Beck FJ, Polman A, Catchpole KR. Designing periodic arrays of metal nanoparticles for light-trapping applications in solar cells. App/ Phys Lett 2009; 95 053115.

15 Catchpole KR, Polman A. Design principles for particle plasmon enhanced solar cells. Appl Phy Lett 2008; 93: 191113.

16 Catchpole KR, Polman A. Plasmonic solar cells. Opt Express 2008; 16: 21793 21800.

17 Pillai S, Green MA. Plasmonics for photovoltaic applications. Sol Energ Mater Sol C Cells 2010; 94: 1481-1486.

18 Beck FJ, Polman A, Catchpole KR. Tunable light trapping for solar cells using localized surface plasmons. J Appl Phys 2009; 105: 114310.

19 Munday JN, Atwater HA. Large integrated absorption enhancement in plasmonic solar cells by combining metallic gratings and antireflection coatings. Nano Lett $2011 ; 11$ 2195-2201.

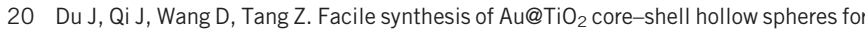
dye-sensitized solar cells with remarkably improved efficiency. Energy Environ Sci 2012; 5: 6914-6918

21 Rand BP, Peumans P, Forrest SR. Long-range absorption enhancement in organic tandem thin-film solar cells containing silver nanoclusters. J Appl Phys 2004; 96: 7519-7526.

22 Kim SS, Na SI, Jo J, Kim DY, Nah YC. Plasmon enhanced performance of organic solar cells using electrodeposited Ag nanoparticles. App/ Phys Lett 2008; 93: 073307.

23 Wu JL, Chen FC, Hsiao YS, Chien FC, Chen P et al. Surface plasmonic effects of metallic nanoparticles on the performance of polymer bulk heterojunction solar cells. ACS Nano 2011; 5: 959-967.

24 Wang DH, Kim DY, Choi KW, Seo JH, Im SH et al. Enhancement of donor-acceptor polymer bulk heterojunction solar cell power conversion efficiencies by addition of $\mathrm{Au}$ nanoparticles. Angew Chem Int Ed 2011; 50: 5519-5523

25 Wang CC, Choy WC, Duan C, Fung DD, Sha WE et al. Optical and electrical effects of gold nanoparticles in the active layer of polymer solar cells. J Mater Chem 2012; 22 1206-1211.

26 Konda RB, Mundle R, Mustafa H, Bamiduro O, Pradhan AK et al. Surface plasmon excitation via Au nanoparticles in $\mathrm{n}-\mathrm{CdSe} / \mathrm{p}-\mathrm{Si}$ heterojunction diodes. Appl Phys Let 2007; 91: 191111.

27 Hägglund C, Zäch M, Kasemo B. Enhanced charge carrier generation in dye sensitized solar cells by nanoparticle plasmons. Appl Phys Lett 2008; 92: 013113

28 Standridge SD, Schatz GC, Hupp JT. Distance dependence of plasmon-enhanced photocurrent in dye-sensitized solar cells. J Am Chem Soc 2009; 131: 8407-8409.

29 Qi J, Dang X, Hammond PT, Belcher AM. Highly efficient plasmon-enhanced dyesensitized solar cells through metal@oxide core-shell nanostructure. ACS Nano 2011; 5: 7108-7116.

30 Brown MD, Suteewong T, Kumar RS, D'Innocenzo V, Petrozza A et al. Plasmonic dyesensitized solar cells using core-shell metal-insulator nanoparticles. Nano Let 2011; 11: 438-445.

31 Choi $\mathrm{H}$, Chen WT, Kamat PV. Know thy nano neighbor. Plasmonic versus electron charging effects of metal nanoparticles in dye-sensitized solar cells. ACS Nano 2012; 6: 4418-4427.

32 Spinelli $\mathrm{P}$, Polman A. Prospects of near-field plasmonic absorption enhancement in semiconductor materials using embedded Ag nanoparticles. Opt Express 2012; 20 : A641-A654.

33 Green MA, Pillai S. Harnessing plasmonics for solar cells. Nature Photonics 2012; 6: 130-132.

34 Ferry VE, Sweatlock LA, Pacifici D, Atwater HA. Plasmonic nanostructure design for efficient light coupling into solar cells. Nano Lett 2008; 8: 4391-4397.

35 Ferry VE, Munday JN, Atwater HA. Design considerations for plasmonic photovoltaics. Adv Mater 2010; 22: 4794-4808.

36 Wang W, Wu S, Reinhardt K, Lu Y, Chen S. Broadband light absorption enhancement in thin-film silicon solar cells. Nano Lett 2010; 10: 2012-2018.
37 Ferry VE, Polman A, Atwater HA. Modeling light trapping in nanostructured solar cells. ACS Nano 2011; 5: 10055-10064.

38 Ferry VE, Verschuuren MA, Li HB, Schropp RE, Atwater HA et al. Improved redresponse in thin film a-Si:H solar cells with soft-imprinted plasmonic back reflectors. App/ Phys Lett 2009; 95: 183503.

39 Zhu J, Hsu CM, Yu Z, Fan S, Cui Y. Nanodome solar cells with efficient light management and self-cleaning. Nano Lett 2010; 10: 1979-1984.

40 Bowden N, Brittain S, Evans AG, Hutchinson JW, Whitesides GM. Spontaneous formation of ordered structures in thin films of metals supported on an elastomeric polymer. Nature 1998; 393: 146-149.

41 Guo CF, Nayyar V, Zhang Z, Chen Y, Miao J et al. Path-guided wrinkling of nanoscale metal films. Adv Mater 2012; 24: 3010-3014.

42 Kim JB, Kim P, Pégard NC, Oh SJ, Kagan CR et al. Wrinkles and deep folds as photonic structures in photovoltaics. Nature Photonics 2012; 6: 327-332.

43 Fabry C, Pérot A. Sur les franges des lames minces argentées et leur application à la mesure de petites épaisseurs d'air. Ann Chim Phys 1897; 12: 459-501.

44 Hadley LN, Dennison DM. Reflection and transmission interference filters (Part I. Theory). J Opt Soc Am 1947; 37: 451-465.

45 Hadley LN, Dennison DM. Reflection and transmission interference filters (Part II. Experimental, comparison with theory, results). J Opt Soc Am 1948; 38: 483-496.

46 Pendry JB, Holden AJ, Stewart WJ, Youngs I. Extremely low frequency plasmons in metallic mesostructures. Phys Rev Lett 1996; 76: 4773-4776.

47 Pendry JB, Holden AJ, Robbins DJ, Stewart WJ. Magnetism from conductors and enhanced nonlinear phenomena. IEEE Trans Microwave Theory Tech 1999; 47: 2075-2084

48 Smith DR, Padilla WJ, Vier DC, Nemat-Nasser SC, Schultz S. Composite medium with simultaneously negative permeability and permittivity. Phys Rev Lett 2000; 84: 4184-4187.

49 Schurig D, Mock JJ, Justice BJ, Cummer SA, Pendry JB et al. Metamaterial electromagnetic cloak at microwave frequencies. Science 2006; 314: 977-980.

50 Liu X, Starr T, Starr AF, Padilla WJ. Infrared spatial and frequency selective metamaterial with near-unity absorbance. Phys Rev Lett 2010; 104: 207403

51 Pendry JB. Negative refraction makes a perfect lens. Phys Rev Lett 2000; 85: 3966 3969.

52 Padilla WJ, Basov DN, Smith DR. Negative refractive index metamaterials. Mater Today 2006; 9: 28-35.

53 Smith DR, Pendry JB, Wiltshire MC. Metamaterials and negative refractive index. Science 2004; 305: 788-792.

54 Shalaev VM. Optical negative-index metamaterials. Nature Photonics 2007; 1: 41-48.

55 Soukoulis CM, Wegener M. Past achievements and future challenges in the development of three-dimensional photonic metamaterials. Nature Photonics 2011; 5: 523-530.

56 Hao J, Wang J, Liu X, Padilla WJ, Zhou L et al. High performance optical absorber based on a plasmonic metamaterial. Appl Phys Lett2010; 96: 251104.

57 Zhang S, Fan W, Minhas BK, Frauenglass A, Malloy KJ et al. Midinfrared resonant magnetic nanostructures exhibiting a negative permeability. Phys Rev Lett 2005; 94 037402.

58 Padilla WJ, Aronsson MT, Highstrete C, Lee M, Taylor AJ et al. Electrically resonant terahertz metamaterials: theoretical and experimental investigations. Phys Rev $B$ 2007; 75: 041102(R).

59 Gansel JK, Thiel M, Rill MS, Decker M, Bade K et al. Gold helix photonic metamaterial as broadband circular polarizer. Science 2009; 325: 1513-1515.

60 Aydin K, Ferry VE, Briggs RM, Atwater HA. Broadband polarization-independent resonant light absorption using ultrathin plasmonic super absorbers. Nat Commun 2011; 2: 517 .

61 Bayindir M, Aydin K, Ozbay E, Markoš P, Soukoulis CM. Transmission properties of composite metamaterials in free space. Appl Phys Lett 2002; 81: 120-122.

62 Greegor RB, Parazzoli CG, Li K, Tanielian MH. Origin of dissipative losses in negative index of refraction materials. App/ Phys Lett 2003; 82: 2356-2358.

63 García-Meca C, Ortuño R, Rodriguez-Fortuño FJ, Martí J, Martínez A. Double-negative polarization-independent fishnet metamaterial in the visible spectrum. Opt Lett 2009; 34: 1603-1605.

64 Xiao SM, Chettiar UK, Kildishev AV, Drachev VP, Shalaev VM. Yellow-light negativeindex metamaterials. Opt Lett 2009; 34: 3478-3480.

65 Wang Y, Sun T, Paudel T, Zhang Y, Ren Z et al. Metamaterial-plasmonic absorber structure for high efficiency amorphous silicon solar cells. Nano Lett 2012; 12: $440-445$

66 Kats MA, Blanchard R, Genevet P, Capasso F. Nanometre optical coatings based on strong interference effects in highly absorbing media. Nat Mater 2013; 12: 20-24.

67 Sun T, Akinoglu EM, Guo CF, Paudel T, Gao J et al. Enhanced broad-band extraordinary optical transmission through subwavelength perforated metallic films on strongly polarizable substrates. Appl Phys Lett 2013; 102: 101114.

68 Heavens OS. Optical Properties of Thin Solid Films. New York: Dover; 1965.

69 Guo CF, Sun T, Wang Y, Gao J, Liu Q et al. Conductive black silicon surface made by silver nanonetwork assisted etching. Small 2013; 9: 2415-2419.

70 Guo CF, Sun T, Liu Q, Suo Z, Ren Z. Highly stretchable and transparent nanomesh electrodes made by grain boundary lithography. Nat commun 2013; 5: 3121.

$71 \mathrm{Wu} \mathrm{H}$, Kong D, Ruan Z, Hsu PC, Wang S et al. A transparent electrode based on a meta nanotrough network. Nat Nanotech 2013; 8: 421-425.

72 van de Groep J, Spinelli P, Polman A. Transparent conducting silver nanowire networks. Nano Lett 2012; 12: 3138-3144.

73 Mauthner F, Weiss W. Solar Heat Worldwide: Solar Heating \& Cooling Programme. Paris: International Energy Agency; 2013. 
74 Kraemer D, Poudel B, Feng HP, Caylor JC, Yu B et al. High-performance flat-panel solar thermoelectric generators with high thermal concentration. Nat Mater 2011; 10: 532-538.

75 Kennedy CE. Review of mid- to high-temperature solar selective absorber materials. National Renewable Energy Laboratory: Golden, CO, USA, 2002. Report no. NREL/ TP-520-31267

76 Zhang QC. Optimizing analysis of W-AIN cermet solar absorbing coatings. J Phys D App/ Phys 2001; 34: 3113-3120.

77 Olson KD, Talghader JJ. Absorption to reflection transition in selective solar coatings. Opt Express 2012; 20: A554-A559.

78 Tabor H. Selective radiation. I: wavelength discrimination. Bull Res Council Isr 1956; 5A: 119-134.

79 Orel B, Spreizer H, Slemenik Perše L, Fir M, Šurca Vuk A et al. Silicone-based thickness insensitive spectrally selective (TISS) paints as selective paint coatings for coloured solar absorbers (Part I). Sol Energ Mat Sol C 2007; 91: 93-107.

80 Teixeira V, Sousa E, Costa MF, Nunes C, Rosa L et al. Spectrally selective composite coatings of $\mathrm{Cr}-\mathrm{Cr}_{2} \mathrm{O}_{3}$ and $\mathrm{Mo}-\mathrm{Al}_{2} \mathrm{O}_{3}$ for solar energy applications. Thin Solid Films 2001; 392: 320-326.

81 Orel B, Orel ZC, Radoczy I. Thickness sensitive spectrally selective (TSSS) paint for solar collectors: optical properties, surface characterization and application properties. Sol Energ Mater 1988; 18: 97-107.

82 Fan JC, Spura SA. Selective black absorbers using rf-sputtered $\mathrm{Cr}_{2} \mathrm{O}_{3} / \mathrm{Cr}$ cermet films. Appl Phys Lett 1977; 30: 511-513.

83 Craighead HG, Buhrman RA. Optical-properties of selectively absorbing $\mathrm{Ni} / \mathrm{Al}_{2} \mathrm{O}_{3}$ composite films. Appl Phys Lett 1977; 31: 423-425.

84 Mcdonald GE. Spectral reflectance properties of black chrome for use as a solar selective coating. Sol Energy 1975; 17: 119-122.

85 Narayanaswamy A, Chen G. Thermal emission control with one-dimensional metallodielectric photonic crystals. Phys Rev B 2004; 70: 125101

86 Barshilia HC, Selvakumar N, Vignesh G, Rajam KS, Biswas A. Optical properties and thermal stability of pulsed-sputter-deposited $\mathrm{Al}_{x} \mathrm{O}_{y} / \mathrm{Al} / \mathrm{Al}_{x} \mathrm{O}_{y}$ multilayer absorber coatings. Sol Energ Mat Sol C 2009; 93: 315-323.

87 Nuru ZY, Arendse CJ, Khamlich S, Maaza M. Optimization of $\mathrm{Al}_{x} \mathrm{O}_{y} / \mathrm{Pt} / \mathrm{Al} \mathrm{O}_{x} \mathrm{O}_{y}$ multilayer spectrally selective coatings for solar-thermal applications. Vacuum 2012; 86 : 2129-2135.

88 Li XF, Chen YR, Miao J, Zhou P, Zheng YX et al. High solar absorption of a multilayered thin film structure. Opt Express 2007; 15: 1907-1912.

89 Wu YW, Zheng WF, Lin LM, Qu Y, Lai FC. Colored solar selective absorbing coatings with metal Ti and dielectric AIN multilayer structure. Sol Energ Mat Sol C 2013; 115: 145-150.

90 Selvakumar N, Barshilia HC, Rajam KS, Biswas A. Structure, optical properties and thermal stability of pulsed sputter deposited high temperature $\mathrm{HfO} \times / \mathrm{Mo} / \mathrm{HfO}_{2}$ solar selective absorbers. Sol Energ Mat Sol C 2010; 94: 1412-1420.
91 Lampert CM, Washburn J. Microrstructure and optical properties of black chrome before and after exposure to high temperatures. In: Proceedings of the Second Annual Conference on Absorber Surfaces for Solar Receivers; 24-25 January 1979; Boulder, CO, USA.

92 Boström T, Wäckelgård E, Westin G. Solution-chemical derived nickel-alumina coatings for thermal solar absorbers. Sol Energy 2003; 74: 497-503.

93 Boström TK, Wäckelgård E, Westin G. Anti-reflection coatings for solution-chemically derived nickel-alumina solar absorbers. Sol Energ Mat Sol C 2004; 84: 183-191.

94 Antonaia A, Castaldo A, Addonizio ML, Esposito S. Stability of $\mathrm{W}-\mathrm{Al}_{2} \mathrm{O}_{3}$ cermet based solar coating for receiver tube operating at high temperature. Sol Energ Mat Sol C 2010; 94: 1604-1611.

95 Cheng J, Wang C, Wang W, Du X, Liu Y et al. Improvement of thermal stability in the solar selective absorbing Mo-Al $\mathrm{O}_{3}$ coating. Sol Energ Mat Sol C 2013; 109: 204-208.

96 Zhang QC, Mills DR. Very low-emittance solar selective surfaces using new film structures. J Appl Phys 1992; 72: 3013-3021.

97 Zhang QC, Shen YG. High performance W-AIN cermet solar coatings designed by modelling calculations and deposited by DC magnetron sputtering. Sol Energ Mat Sol C 2004; 81: 25-37.

98 Zhang QC. Stainless-steel-AIN cermet selective surfaces deposited by direct current magnetron sputtering technology. Sol Energ Mat Sol C 1998; 52: 95-106.

99 Zhang QC, Mills DR. New cermet film structures with much improved selectivity for solar thermal applications. Appl Phys Lett 1992; 60: 545-547.

100 Wang X, Li H, Yu X, Shi X, Liu J. High-performance solution-processed plasmonic Ni nanochain- $\mathrm{Al}_{2} \mathrm{O}_{3}$ selective solar thermal absorbers. Appl Phys Lett 2012; 101 203109.

101 Byrne DM, Brouns AJ, Case FC, Tiberio RC, Whitehead BL et al. Infrared mesh filters fabricated by electron-beam lithography. J Vac Sci Tech B Microelectron Nanometer Struct 1985; 3: 268-271.

102 Jefimovs K, Laukkanen J, Vallius T, Pilvi T, Ritala M et al. Free-standing inductive grid filter for infrared radiation rejection. Microelectron Eng 2006; 83: 1339-1342.

103 Lee J, Lee P, Lee H, Lee D, Lee SS et al. Very long Ag nanowire synthesis and its application in a highly transparent, conductive and flexible metal electrode touch panel. Nanoscale 2012; 4: 6408-6414.

(c) (1)

This work is licensed under a Creative Commons Attribution 3.0 Unported License. The images or other third party material in this article are included in the article's Creative Commons license, unless indicated otherwise in the credit line; if the material is not included under the Creative Commons license, users will need to obtain permission from the license holder to reproduce the material. To view a copy of this license, visit http://creativecommons.org/ licenses/by/3.0/ 